\title{
DE LA CONFRONTACIÓN ENTRE LA ASTROLOGÍA Y EL PRIMER CRISTIANISMO AL APROVECHAMIENTO DE LOS ARQUETIPOS ASTROLÓGICOS POR EL HUMANISMO CRISTIANO
}

\author{
Luis Miguel Vicente García \\ Universidad Autónoma de Madrid
}

\section{RESUMEN}

Se estudian las reacciones de los primeros pensadores cristianos frente a la astrología, los antecedentes clásicos en que se basaron, y el posterior aprovechamiento de los símbolos y arquetipos astrológicos por la filosofía y literatura del humanismo cristiano.

Palabras clave: Astrología, cristianismo, símbolos, arquetipos astrológicos.

\begin{abstract}
It is studied the first reactions of Christian philosophers against Astrology; the classical sources for their arguments, and the late use of Astrological symbols and archetypes in Literature and Philosophy by Christian Humanism.
\end{abstract}

Key words: Astrology, Christian Humanism, astrological symbols and archetypes.

\section{ANTECEDENTES CLÁSICOS}

En general los historiadores de la astrología coinciden en señalar las antiguas civilizaciones de Mesopotamia y del Nilo como la cuna de la astrología occidental. ${ }^{1}$ Las estrellas eran consideradas en estos pueblos de la Antigüedad como la fuente de todos los cambios y también como signos que podían interpretarse. La adivinación por los astros entre los sacerdotes babilónicos se centraba en profecías de carácter primitivo, tomando como base los eclipses, y se centraban en la vida de los reyes. ${ }^{2}$ Este pueblo hacía también predicciones meteorológicas de acuerdo con el color de los planetas al levantarse o al ponerse. Paulatinamente el campo de acción de la astrología se extendió a los sucesos cotidianos y amplió su difusión social. Los $Z i$ gurats o templos mesopotámicos, con sus siete divisiones, reproducían los siete planetas del cielo; en ellos se desarrollaron cálculos matemáticos de cierto avance que contribuyeron al establecimiento de un calendario en Occidente. Los planetas fueron divinizados por los mesopotámicos, que concibieron, sobre la base de la regularidad de sus movimientos, una especie 
de «determinismo universal» (Halbronn 173) Saturno, en especial, era tenido como el rey del cielo.

Los griegos y romanos consideraban a Berosus, sacerdote del templo de Bel en Babilonia, como el más antiguo autor de tratados de astrología. En cuanto a la civilización egipcia, no ha sido posible determinar hasta el momento cuál sería su contribución original al saber astrológico, pero lo cierto es que esta disciplina tuvo entre ellos un cultivo más desarrollado que entre los mesopotámicos, de los que tomarían la iniciativa. La tradición astrológica más importante atribuida a los egipcios son los libros de Hermes Trimegisto, al que se consideraba como el padre de la astrología; los libros herméticos tuvieron una inmensa difusión en el Occidente medieval; a Hermes se le atribuía la división del zodiaco en doce casas. Pensadores cristianos como Clemente de Alejandría y Eusebio testimonian, en época tardía, el prestigio y el enorme cultivo que tenía la astrología entre los egipcios. Eran los planetas para éstos los causantes del fin de las monarquías, las pestes, las revoluciones y los fenómenos naturales como los terremotos, las lluvias, etc. Está también documentada la costumbre de hacer horóscopos individuales entre los egipcios, al menos en época tardía: contamos con el testimonio de Proclus, un filósofo griego neoplatónico del siglo $\mathrm{V}^{3}$

Mucho material astrológico de estas civilizaciones sobrevivió en Grecia en la compilación de Ptolomeo (siglo II) Pero los griegos en general no demostraron interés por la astrología babilónica, si no es en su desarrollo mitológico, filosófico o religioso. ${ }^{4} \mathrm{La}$ astrología en cuanto a ciencia de la adivinación sólo se extendió en el mundo helénico después de las conquistas de Alejandro Magno, con la incorporación de los conocimientos de las civilizaciones conquistadas (la caldea, la persa, la egipcia y la india)

Grecia tenía una serie de tradiciones filosóficas como el pitagorismo - - cuyas teorías sobre la música de las esferas parecen estar relacionadas con estudios astrológicos egipcios- o el estoicismo, que constituían un sustrato idóneo para aceptar las teorías astrológicas.

Los estoicos eran, por otra parte, dados a las adivinaciones de todo tipo. Era general en las escuelas filosóficas griegas distinguir entre el cielo y la tierra como en la base de toda la filosofia china.

Con Platón se difunde la idea de que los cuerpos celestiales eran de diferente naturaleza que los terrestres. Los celestes eran divinos, inmortales, poseedores de inteligencia y alma. ${ }^{5} \mathrm{De}$ la tradición platónica hereda Orígenes la idea de la jerarquía de los cuerpos celestes dotados de alma.

Por otro lado, Aristóteles también defendía la diferencia entre una región sublunar y otra supralunar; la luna marcaba el límite entre una región y otra. Un cuerpo del mundo celestial era eterno y tenía movimiento circular mientras que los cuerpos terrestres se movían en línea recta (De Caelo 1 iii) Estos últimos estaban además compuestos por los cuatro elementos - tierra, agua, aire, fuego- mientras que los celestes están formados de un quinto elemento, el éter, o quinta esencia, de naturaleza mucho más noble (De Caelo I iii) Los cinco elementos eran considerados cuerpos simples y tenían su movimiento apropiado con relación al centro y a los otros elementos; movimiento que podía ser circular o en línea recta hacia arriba o hacia abajo. El éter se movía circularmente alrededor del borde que separaba a la región sublunar de la celeste. El fuego, el elemento más ligero de los terrenales, se veía impulsado por su naturaleza, a ocupar la parte más alta del mundo sublunar, con un movimiento hacia arriba. El aire también se movía hacia arriba y tendía a quedarse en la región inmediatamente inferior a la del fuego. Por debajo del aire estaba el agua, que junto con la tierra se caracterizaba por tener un movimiento haçia abajo, contrario al del aire y el fuego. La tierra, en último lugar, era el ele-

3 Cf. Halbronn 176.

4 Cf. Bergua 189-190.

5 Cf. Anderson 159. 
mento más pesado. La posición que ocupaba un cuerpo en el Universo era determinada de acuerdo con la naturaléza de su movimiento - hacia arriba, abajo, o circular-; de ese modo cada cuerpo ocupaba su propio lugar en el Universo. Aristóteles tiende a dividir el mundo en cinco niveles delimitados por el movimiento de los cinco elementos. La región celeste se movía en un eterno movimiento circular, que era la causa de los cambios que ocurrían en la tierra. Las estrellas fijas constituían el principio de permanencia, mientras que el movimiento de los planetas - sobre todo el del Sol, y a mucha mayor distancia, la Luna- originaban el principio del cambio. ${ }^{6}$ Los astros evitaban además que cada cuerpo se saliera de su lugar. Pero en la región sublunar no se dan los cuatro elementos en su forma pura; lo cual quiere decir que tampoco tienen los cuerpos formados por estos elementos un movimiento puro (De Generatione 23,28 ) En cambio, los planetas, compuestos de éter, tenían un movimiento propio puro y eterno, sin que las cosas del mundo terrestre pudieran influir en ellos. ${ }^{7}$

No todas las escuelas filosóficas de la Antigüedad aceptaron la teoría de la quinta esencia. Los estoicos no admitían que la materia que formaba la región celestial tuviera que ser distinta de los cuatro elementos que conformaban la región sublunar. Para ellos, el estudio de la naturaleza podía llevar a la predicción; al conocer el mundo que rodea al hombre, y establecer sus leyes, el hombre se libra del miedo, y se conforma con su destino; no en el sentido de la resignación cristiana, sino por conocer las leyes de la naturaleza y poder vivir aceptándolas. La astrología era en ese sentido un arte preciado para los estoicos, pues les permitía tratar de entender las leyes del mundo y obrar en conformidad con ellas. Además, como bien ha señalado Anderson, los arquetipos universales de la astrología atraían más a los estoicos que otros aspectos triviales o cotidianos. Los estoicos, tanto como Platón o Aristóteles, daban pie a la aceptación de las doctrinas astrológicas.

El Timeo de Platón, con su supervivencia a través de la Edad Media, fue una fuente de autoridad constante para los astrólogos y para los practicantes de las ciencias ocultas en general. ${ }^{8}$ En este libro el filósofo expresaba la concepción del mundo como un organismo vivo, cuyas partes estaban estrechamente relacionadas; presentaba además un tipo de teoría de la emanación en términos astrológicos: el alma desciende de los cielos a través de los dioses planetarios que le prestan cada uno sus propios dones. ${ }^{9}$ Toda la organización del mundo de la materia depende de una Inteligencia Ordenadora, la inteligencia de Dios (Timeo 29) Esa inteligencia es la que establece el criterio de la jerarquía, ordenando las cosas en una escala ascendente, de menor a mayor inteligencia (29-31) En un orden tal, ha señalado finamente Anderson, el énfasis recae sobre las ideas en sí mismas y no sobre los fenómenos físicos, que sólo importan en la medida en que demuestran la Inteligencia que les da razón de ser (Anderson 8)

Estas explicaciones astrológicas del Timeo llegaron hasta la Edad Media a través de los comentarios de Calcidus y Macrobius. ${ }^{10}$ Los platónicos, como se verá en el caso de Plotino, no aceptaron, sin embargo, que los planetas fueran la causa de los destinos humanos sino tan sólo signos que ilustraban las correspondencias entre el microcosmos y el macrocosmos, solución que aún mantendrán los neoplatónicos renacentistas como Marcilio Ficino. ${ }^{11}$ También el Timeo influyó enormemente en los primeros pensadores cristianos. La importancia de las teorías fisicas aristotélicas para la aceptación de la astrología por el cristianismo fue un fenómeno sobre todo de los siglos XII y XIII. ${ }^{12}$

\section{Cf. Wedel 3, Lemay 58.}

Cf. Anderson 148-150.

Cf. Wedel 2.

Cf. Bouché-Leclerqc 9-25, Wedel 2.

Cf. Bouché-Leclerqu 26.

Cf. Wedel 2.

12 La aportación de la astrología árabe se estudia en «Una nueva filosofía de la astrología en los siglos XII y XIII: el impacto de las traducciones del árabe y la postura de Santo Tomás de Aquino»). Revista Española de Filosofia Medieval. Universidad de Zaragoza (2002): 249-264 
En cuanto a la astrología propiamente dicha, Eudoxo de Cnido, autor de una teoría sobre los círculos concéntricos, parece ser el primer autor que escribió en griego sobre temas puramente astrológicos. Su influencia se hace patente en autores como Gémino de Rodas, cuya Introducción a los fenómenos fue comentada por Hiparco (siglo II a. d. C.), fundador de la trigonometría, quien descubrió la precesión de los equinoccios, es decir, el movimiento retrógrado de los puntos equinocciales. Sin embargo, no fue hasta Ptolomeo, en época ya de dominación romana - siglo II- cuando la astrología griega se sistematizó en unos tratados, el Tetrabiblos y el Centiloquium, que habrían de influir a toda Europathasta el siglo XVII, en que las teorías heliocéntricas sustituyen el geocentrismo de la visión.astrológica ptolemaica.

Ptolomeo adapta las ideas de Aristóteles, ${ }^{13}$ pero decide fundamentar la astrología, como muy bien ha señalado Wedel, no tanto con criterios filosóficos como apoyándose en la astronomía, lo cual era un intento de seguir la línea «científica» aristotélica y ofrecer una explicación racional del mundo, en vez de una visión mística, como la de Platón. Ptolomeo desarrolla la teoría de los signos, los planetas, las casas y los aspectos zodiacales; distingue una astrología de predicción de sucesos generales y otra individual; para las predicciones generales divide la tierra en siete climas, cada uno bajo la influencia de su propio planeta y constelación. Estas entidades para él tienen una potencia más fuerte que las individualidades humanas, tienen tal poder que pueden, por ejemplo, determinar el color de una raza o la historia de una comunidad.

La concepción del Cosmos en Ptolomeo prescribía una tierra estática alrededor de la cual giraban las estrellas. ${ }^{14}$ Cada casa zodiacal significaba un aspecto de la vida humana, y su valor dependía del planeta - fortunado o infortunado- que estuviera en ellas en el momento del nacimiento. ${ }^{15}$ Este tipo de astrología, basada en una minuciosa correspondencia entre las observaciones astronómicas y el dominio de lo humano, era, en cierto sentido, una radicalización de las teorías peripatéticas y tuvo un enorme éxito en lo sucesivo, hasta la caída del Imperio Romano y la preponderancia de la Iglesia. No obstante, también contó con sus detractores desde muy temprano.

En Grecia, hacia el siglo II de nuestra era, los escépticos desarrollan una serie de argumentos contra la astrología que proporcionan un modelo en toda diatriba posterior, desde Cicerón a San Agustín: cómo explicar, por ejemplo, las diferencias de destino entre los gemelos que nacen a una misma hora o cómo explicar los holocaustos o las tragedias colectivas de seres con diferentes horóscopos. Jacques Halbronn (186) y Wedel (6) atribuyen la primera formulación lógica de estos argumentos al griego Carneades en el siglo II a. d. C., miembro de la Nueva Academia.

Frente a los ataques de Carneades surgió la defensa de Posidonius - 135 a. d. C.- que, junto con Ptolomeo y los estoicos, respondía a las objeciones contra el arte astrológico. Los argumentos de Carneades, a falta del texto original, se conservan en las referencias de Cicerón De Divinatione, y en el libro quinto de De Civitate Dei, de San Agustín. ${ }^{16}$

El propio Cicerón, en su juventud, tradujo al latín un poema de Arato de Soli, los Phaenomena, escrito alrededor de 270 a. d. C., en el que se explicaba el sistema de Eudoxo. Este poema, admirado tanto por griegos como por romanos, fue comentado por Higinio, amigo de Ovidio. ${ }^{17}$

La astrología médica tuvo también una posición importante entre las ciencias de estos tiempos. Se leía el libro de Hipócrates (¿460-377? a. d. C.), De aere, aqua et locis, obra influida 
por los pitagóricos que discute con detalle el valor de la astrología y sus pronósticos en la medicina. Por su parte, la escuela de medicina de Alejandría utilizaba las prognosis, diagnosis e higiene astrológicas en sus métodos.

Con la dominación romana, la astrología extiende sus fronteras por todos sus territorios. Esta ciencia, a pesar de algunos intentos para proscribirla durante el Imperio Romano, captará la atención de todas las clases sociales, aunque no faltaron detractores como Cicerón ( $D e$ Divinatione) o Lucrecio (De Natura Rerum), empeñados en defender el libre albedrío que sentían incompatible con los conocimientos de la astrología, desde la filosofía o desde la sátira. ${ }^{18}$ Catón el Censor (234-149 a. d. C.) amonestaba a los romanos para que se guardaran de las influencias de los sacerdotes caldeos, y el pretor Cneio Cornelio Hispalo expulsó en el año 139 a. d. C. a los astrólogos de Italia. ${ }^{19}$

Pero, en general, la estima de los astrólogos crece en esta época tanto que llegan a tener incluso una función política como consejeros de los emperadores o de los grandes señores. Julio César se servía constantemente de augures y César Augusto protegió la astrología. De hecho, el primer tratado romano sobre este arte, la Astronomica de Marco Manilio (45 a. d. C.) fue dedicado a este emperador.

La astrología sobrevivió épocas de persecución en tiempos de Claudio y de Vespasiano, pero floreció bajo otros reinados. Así, en tiempos de Tiberio y de Nerón, el astrólogo Trasilo y su hijo ocuparon altos cargos políticos. A la muerte de Marco Aurelio, los astrólogos eran ya personajes importantes en la corte imperial, y en tiempos de Constantino, el notario imperial Julio Firmico Materno escribió sus Matemáticas, en ocho libros que trataban del poder y la influencia de las estrellas. Esta obra tuvo una gran influencia hasta entrado el Renacimiento. San Agustín da cuenta de la difusión y aceptación general de la teorías astrológicas todavía en su época. Uno de los últimos autores de tratados de astrología del mundo antiguo fue Juan Lorenzo — conocido también como Lido- de Filadelfia (490-565)

Plotino es caso aparte. ${ }^{20}$ Gracias a él los pensadores cristianos podrán enfrentarse al tema de la astrología con mayor profundidad y liberarse de prejuicios nacidos de una temerosa ignorancia. Plotino les dará a los artistas que siguen la línea de Dante - a los humanistas neoplatónicos - la libertad para usar los arquetipos astrológicos como símbolos de la belleza del universo, sin la necesidad de verlos bajo el esquema causa-efecto que tantos problemas planteaba a los cristianos sobre el tema del libre albedrío.

\section{LAS PRIMERAS REACCIONES DE LOS PENSADORES CRISTIANOS ANTE LA ASTROLOGÍA}

Mientras la Iglesia estuvo perseguida, los autores cristianos ofrecen algunas disquisiciones dispersas sobre el problema de la astrología, pero no abordan el problema de una manera sistemática. ${ }^{21}$ Es a partir del siglo II, cuando el cristianismo empieza a cobrar una posición destacada en la vida del Imperio Romano, cuando se comienza también a atacar las prácticas astrológicas con toda suerte de argumentos. Los primeros apologistas del cristianismo asocian la astrología a las demás artes adivinatorias o mágicas, y las relacionan a todas con lo demoníaco. Pero la atribución de las prácticas astrológicas al poder del diablo suponía, en parte, admitir

18 Cf. Halbronn 119.

19 Cf. Catholic 2.

20 Traté de la aportación de Plotino al problema de la astrología en «Plotino y el problema de las estrellas: una solución para los neoplatónicos» Revista Española de Filosofia Medieval. Universidad de Zaragoza (2000): 189196.

21 Cf. Lainstner 254. 
que la eficacia de la astrología era posible, aunque fuera gracias a la ayuda de Satanás; y esto llevaba a interrogantes más difíciles de contestar; en palabras de Wedel: «how could even demons read the future in the stars unless it was written there? And how distinguish between a prediction through the help of evil spirits and one sanctioned by God?» (pág. 17)

Los astrólogos podían citar en su defensa el libro del Génesis (1 14) para demostrar que los cuerpos celestes fueron creados con el propósito de servir de signos, y otros cuantos pasajes de las Escrituras para avalar el uso legítimo de la astrología. El ejemplo más citado era la estrella que anunció a los Magos el nacimiento de Cristo, pero también el eclipse que anuncia la injusticia de su crucifixión, o los signos que anunciarán su segunda venida. Si bien los primeros pensadores cristianos como Tertuliano y Lactancio condenan la astrología en sus escritos, ${ }^{22}$ también es cierto que el mismo Tertuliano (De idolatria 9 ) reconoce que todas las artes adivinatorias fueron permitidas por Dios hasta la llegada de Cristo que significó el fin del dominio de los diablos sobre el mundo. ${ }^{23}$

Lo mismo hace Ignacio en su Epistola ad Efesios (19) ${ }^{24}$ La estrella de los Magos sirvió para anunciar al Redentor pero, una vez cumplido su propósito, la astrología debía desaparecer como lo probaba, para Tertuliano, el hecho de que los Magos confundieran su camino de regreso. ${ }^{25}$ En De idolatria condena Tertuliano la relación de la astrología con el demonio y afirma el libre albedrío; critica también la importancia que se le daba a la astrología en el Imperio Romano y sugiere la teoría de la causa primera para probar la prioridad de Dios sobre toda forma de conocimiento; el cristiano debe alejarse de las prácticas astrológicas en cualquier caso, como afirma en su tratado Apologeticus adversus gentes pro christianis. Tertuliano compuso también un tratado contra la hipótesis de Hermógenes sobre la materia eternamente existente, y en el Este Metodio atacó igualmente una teoría parecida sostenida por Orígenes. ${ }^{26} \mathrm{La}$ Iglesia del Este, sobre todo Crisóstomo (Homilia in Matheo 6) y Basilio (Homilia 25) ${ }^{27}$ dio a la estrella de los Magos una interpretación diferente, de tal modo que no necesitara en absoluto la existencia de la astrología; para ellos esta estrella no era un cuerpo celeste normal sino un milagro. Eso explicaba que se hubiera movido de Norte a Sur —el camino en que Palestina queda respecto a Persia - en vez de Este a Oeste, como era de esperar. ${ }^{28}$

Parecido a Crisóstomo argumenta Diodorus de Tarso: La estrella de los Magos es para él un poder divino transformado en estrella, ${ }^{29}$ mientras que para Gregorio de Nisa la estrella de Belén, a diferencia de otras que están fijas o móviles en el firmamento, era al tiempo móvil y fija. ${ }^{30}$ Lainstner, en suma, dice que para Abrosiaster, Gregorio de Nisa, Jerónimo y Diodorus, la estrella de los Magos es un fenómeno extra ordinem mundi en un sentido mesiánico. Gregorio Magno, sin embargo no discute, en su homilía sobre la Epifanía, la estrella de los magos pero introduce un fragmento antiastrológico. Maximino el Ariano denuncia a los paganos por su culto a los cuerpos celestes y cita a San Pablo (Rom. 1 20-23) y el Libro de la Sabiduría (13 $1-4)^{31}$

22 Cf. Lainstner 254.

23 Sed magi et astrologi ab oriente venerunt [...] Primi igitur stellarum interpretes natum Christum annuntiaverunt, primi muneraverunt. Hoc nomine Christum (opinor) sibi obligaverunt. Quid tum? Ideo nunc et mathematicis patrociinabitur illorum magorum religio? De Christo scilicet est mathesis hodie stellas Christi, non Saturni et Martis et cujusque, ex eodem ordine mortuorum observat et praedicat. At enim scientia illa usque ad Evangelium fuit concessa, ut Christo edito nemo exinde nativitatem alicujus de coelo interpretetur (Patrologia L. 1 474-478)

24 Cf. Wedel 18, n. 1.

25 Cf. Wedel 18.

26 Cf. Lainstner 254.

27 Cf. Wedel 18 n. 2.

28 Cf. Wedel 18.

29 Cf. Patrologiae G. 103877 A.

30 Cf. Patrologiae G. 461133 D, Lainstner 261

31 Cf., Lainstner 261 
Por su parte; Orígenes y los gnósticos se preocuparon sobre todo de defender la existencia del libre albedrio. El argumento de Orígenes es una aplicación de los métodos de la lógica: los astros no pueden ser la causa del destino humano puesto que la causa ha de preceder siempre al efecto y la carta natal es simultánea al nacimiento y no precedente. ${ }^{32}$. Sin embargo, Orígenes acepta, como los neoplatónicos, que las estrellas si no causa, sí pueden ser signos a base de los cuales predecir. ${ }^{33}$ Esta concesión a la astrología por parte de Orígenes y los gnósticos, fue pronto eliminada y considerada herética, cuando el Cristianismo se estableció como la religión oficial del-Imperio.

Después del siglo III Diocleciano prohíbe la astrología, ${ }^{34}$ y durante los siglos IV y V las diatribas contra este arte se hacen más copiosas e intransigentes. Lainstner señala la abundancia en esta época de oponentes a la astrología de los paganos: Hierocles, Salustio y Cirilo de Alejandría lanzan cada uno sus invectivas contra los astrólogos 35

En general, estos ataques aparecen todavía ligados al tema del fatalismo o al comentario de breves pasajes bíblicos. Entre los primeros defensores del libre albedrío contra el determinismo astrológico destaca Lainstner los tratados de Gregorio de Nisa, el discurso sobre la naturaleza humana de Nemesio y dos poemas, uno de Gregorio Nacianceno, De Providentia, en el que se menciona la conversión de los Magos que, al contemplar a Cristo, abandonan sus antiguas prácticas de astrología; y otro poema en latín de Ambrosiaster, la Quaestio $C X V$, junto con una serie de capítulos de la Ciudad de Dios, de San Agustín.

Como comentarios a pasajes bíblicos, se entreveran ataques contra la astrología en los comentarios de Basilio el Grande, Procopio de Gaza, Ambrosio, y Julián de Halicarnaso ${ }^{36}$ Los principales argumentos que utilizan estos autores serán repetidos una y otra vez por los autores cristianos y muchos de ellos, como se ha señalado, fueron ya forjados por autores paganos del período helenístico, o de la Nueva Academia, como Carneades y los estoicos. ${ }^{37}$ Boll, a quien sigue Lainstner, demuestra cómo desde el siglo II a. de C. hasta el período bizantino, se dan dos clases de argumentos contra el determinismo astrológico. El primer grupo de argumentos gira en torno a la pregunta: «¿cómo se pude sostener que las peculiaridades físicas y mentales de un individuo dependan de las características de las estrellas a la hora de su concepción o nacimiento cuando en realidad muchas de tales características se dan en todos los miembros de un mismo pueblo?» En esa línea se sitúa el argumento de San Agustín sobre los gemelos. En segundo lugar, los autores cristianos atacan la teoría astrológica que adjudicaba ciertos territorios geográficos al dominio o influjo de varios signos o planetas. En ese sentido argumentaron los Santos Padres que la observancia de ciertas leyes o costumbres, como la Ley Mosaica, era común a todos los miembros de un pueblo por encima de su situación geográfica, y por lo tanto, no podía estar determinada por los signos y planetas; la misma objeción presentan las catástrofes colectivas. ${ }^{38}$

Lainstner señala a Gregorio de Nisa y a Ambrosiaster como los pioneros en introducir experiencias personales entre los ataques contra la astrología, cosa que será la tónica general en San Agustín. ${ }^{39}$

32 Wedel reseña este argumento reseñado en Eusebio Praeparatio Evangelica 6. II (19, n.1); véase Patrologiae $G 21478$ y ss.

33 Cf. Wedel 19.

34 Cf. Halbronn 195.

35 Cf., Lainstner 255

36 Cf. Lainstner 255-256

37 Cf. Lainstner 256, Boll Studien 183 y ss., Wedel 21.

38 Cf. Lainstner 257.

39 Véase mi articulo «San Agustín, San Gregorio y San Isidoro ante el problema de las estrellas: fundamentos para el rechazo frontal de la astrologia» Revista Española de Filosofia Medieval. Universidad de Zaragoza 8 (2001): 187-203. 
En la Iglesia de Occidente la literatura antiastrológica fue mucho más escasa: Lainstner menciona una novela del pseduo-Clemente y la familiaridad de Ambrosio con Basilio y Orígenes, mientras que San Agustín se basa en Cicerón; por último este estudioso apunta también la existencia de una obra a principios del siglo V, los Hechos de San Sebastián, falsamente atribuidos a San Ambrosio, donde el santo visita el laboratorio astrológico de Chromantius y ocasiona la conversión de éste después de que un mensajero angélico desciende del Cielo y destruye los ídolos. La Iglesia de Occidente se dedicó a condenar duramente tanto las prácticas de los astrólogos profesionales como las supersticiones populares. El libro cuarto del Códice Teodosiano defiende la ortodoxia con una serie de párrafos contra los judíos y los herejes; en èl libro noveno, que se ocupa de los distintos crímenes posibles, se consignan las prácticas supersticiosas y se menciona específicamente a los astrólogos: «cesset mathematicorum tractatus» ${ }^{40}$

En el año 386 los emperadores ofrecen el perdón en la Constitutio Simordiana a diversos ofensores, con la excepción de los criminales mayores, entre los que se cuentan los «in astra pecantes.» Por último, la astrología fue condenada en el Concilio de Toledo del año 400 y en el concilio de Braga celebrado entre los años 560 y 565, aunque la condena recaía específicamente sólo sobre los priscilianistas. ${ }^{41}$ El papa León I también condena duramente a los priscilianistas y ataca duramente sus creencias en la astrología en una carta. ${ }^{42}$

León I considera la creencia astrológica de que los cuerpos y las almas de los hombres están regidos por las estrellas como la onceava blasfemia de los herejes, al tiempo que condena el fatalismo. En la segunda redacción hecha por Dionisio Exiguo de la primera colección y traducción de los Cánones de la Iglesia, adoptada por la Iglesia Romana, hay sólo una mención y condena de la astrología directamente, lo cual, según Lainstner, contrasta con la abundancia de condenas de la magia y las supersticiones populares. La mención de la astrología y los astrólogos parece ser poco frecuente según este investigador en la literatura penitencial. Lainstner señala cómo en los libros penitenciales la palabra «mathematici» ha perdido su significado original y se asocia con la brujería y la invocación de demonios.

A partir del siglo VI los autores no añaden casi nada nuevo a los ataques contra la astrología, que cada vez va siendo un tema más literario que vivo. ${ }^{43}$ Entre los siglos VI y VIII los autores cristianos añaden poco: Gregorio de Tours compone un pequeño tratado astronómico, adhiriéndose a la astronomía científica y dejando de lado todo propósito astrológico. ${ }^{44} \mathrm{Sin}$ embargo, como Lainstner señala, en sus escritos sobre la Historia de los francos menciona varios hechos portentosos relacionados con las estrellas. Del mismo modo Beda el Venerable, aunque condena la astrología en un capítulo titulado «De effectiva lunae potentia», como San Basilio y San Ambrosio, acepta ciertas influencias de la luna en el crecimiento de los animales y las plantas y en el establecimiento del tiempo apropiado para determinadas labores agrícolas, así como también menciona el significado de los cometas asociado a catástrofes, tal era común incluso en las historias naturales como la de Plinio. Los fenómenos astronómicos irregulares o inesperados, como los eclipses y cometas, solían verse en general, y más allá de la influencia de una astrología profesional, como signos que anunciaban desastres fruto de la inmoralidad o del pecado humanos.

\footnotetext{
40 Apud Lainstner 263

41 Cf. Lainstner 264

42 «Ad hanc insaniam pertinet prodigiosa illa totius humani corporis per duodecim caeli signa distinctio ut diversis partibus diversae praesideant potestates; et creatura quam deus ad imaginem suam fecit, in tanta sit obligatione siderum in quanta est connexione membrorum. Merito patres nostri, sub quorum temporibus haeresis haec nefanda prorupit, per totum mundum instanter egere ut impius furor ab universa ecclesia pelleretur» (Apud Lainstner, pág. 264)

43 Cf. Wedel, 26

44 Cf. Lainstner, 266
} 
Esta será también la línea de San Isidoro. Casiodoro pondera el valor de la astronomía para la navegación y la agricultura y condena la astrología basándose en San Agustín y en San Basilio. $^{45}$

Especialmente interesante es la pervivencia sugerida por Fontaine de la tradición neoplatónica en el cristianismo latino, lo cual supondría adoptar una posición intermedia y aceptar, como habían hecho Plotino y Orígenes, que podía existir libre albedrío, sin rechazar totalmente el influjo de las estrellas; para Fontaine tal postura fue conocida en el cristianismo latino en la obra de Calcidius, comentador del Timeo ${ }^{46}$ a este tipo de astrología la llama Fontaine «astrologie sémantique» porque las estrellas sirven de signos más que de causas y la astrología es «réduite à une simple science d'observation des signes». ${ }^{47}$

Es un tipo de astrología semántica lo que construyen los pensadores cristianos, seguidores del ejemplo de Dante, aprovechando la libertad de interpretación de los arquetipos astrológicos que habían dado Plotino y los pensadores neoplatónicos. Llevando a la astrología al terreno de la filosofía y de la literatura.

\section{APROVECHAMIENTO FILOSÓFICO Y LITERARIO DE LOS ARQUETIPOS ASTROLÓGICOS}

La literatura del XIV y del XV reflejará el auge de las cuestiones astrológicas como lo hará el humanismo italiano del que nace el Renacimiento. Las cuestiones astrológicas de las que se hizo eco la literatura fueron varias: determinismo y libre albedrío, el orden universal y sus símbolos, el uso religioso y político de esos símbolos, el problema del carácter... la creatividad literaria tomó de la astrología lo que le vino bien para sus intereses estéticos, moralizantes y propagandísticos y la moral religiosa de turno siempre veló por establecer los límites de la relación con la astrología dentro de su ortodoxia.

La astrología ofrecía una imagen perfecta de los nexos universales, una manifestación material del orden espiritual del cosmos. Por encima de su colosal rueda de la vida el cristianismo colocó su jerarquía de seres espirituales en la escala hasta Dios. Fue en muchos sentidos un conocimiento que despertó el interés y la imaginación de los poetas y escritores, sobre todo los más apegados a la idea del poeta sabio, el poeta filósofo, el poeta que podía leer el universo como un espejo alegórico de verdades profundas, e interpretar en él el privilegiado destino de los nobles mecenas.

Los dezires por su vocación oracular, por su tono solemne y épico, usaron el cañamazo de símbolos astrológicos para construir las virtudes de sus patrocinadores. Así se hizo un zodíaco a la carta para cada uno de los personajes nobles que protagonizaban los dezires. ${ }^{48} \mathrm{Y}$ también se hizo un zodiaco a lo divino. Tampoco eso era nuevo: en el tetramorfo, con el emblema de los cuatro evangelistas, vemos también el emblema de los cuatro signos fijos del zodiaco: El león de San Marcos y de Leo; el toro de San Lucas y de Tauro; El águila de San Mateo y de Escorpio y El hombre de Acuario y de San Juan. La analogía entre los símbolos del zodiaco y algunas figuras religiosas se pierde en el tiempo.

\footnotetext{
45 Cf. Lainstner, 267

46 Cf. Fontaine 291

47 Fontaine 292

48 Al día de hoy, y hasta donde me consta, falta un estudio sistemático del dezir como género literario en España. Y para cuando un estudio riguroso aparezca, deberá tener en cuenta de un modo primordial el uso de los arquetipos astrológicos en esos poemas, ya que casi todo el cañamazo alegórico de estos poemas remite a ese tipo de símbolos y arquetipos, algunos sacados tal cual de la astrologia, y otros modificados por la creatividad del poeta para un uso estético y retórico distinto.
} 
Los humanistas del primer Renacimiento se fascinaron con la concepción del mundo que encontraron en el estudio de la astronomía-astrología; algunos como Lulio o Picco della Mirandola descubrieron el mundo esotérico desde la cábala a la astrología o la numerología y fueron más allá:de lo que las creencias oficiales de la iglesia permitían. Con ellos el conocimiento heredado de tantas civilizaciones se vuelve universal, intenta eliminar la censura y los prejuicios y estudiar esa herencia hermética que permite dar con el significado anagógico de los textos espirituales.

La idea medieval de que el orden social y político seguía inspirándose en el celestial, se afianza en los dezires como alabanza de nobles que son, con su carga de manual de príncipes, pues está lleno de consejos para gobernar o de alabanzas sobre las hazañas que ya ocupan un lugar entre los inmortales. El mundo astrológico que reinventa Dante para la literatura ${ }^{49}$ causa fascinación porque su estructura se muestra como una explicación racional del universo cristiano, que se adorna de toda la sabiduría clásica.

El dezir sirve para amonestar y criticar también lo que ha producido un mal moral y roto la armonía con Dios. El poeta hace de intermediario, de vate y de autoridad moral. No cabe nada que no sea solemne. En la epístola moral caben otros registros pero en el dezir sólo hay espacio para lo épico, lo alegórico y lo panegírico.

También hubo en la Edad Media preocupación por estudiar el carácter del ser humano. La sicología medieval, como la que se estudia en El Corbacho, está estrechamente ligada a la astrología y sus ideas. ${ }^{50}$

La astrología era un espejo de los ciclos del año, marcados por el discurrir del sol por las doce constelaciones. El año natural o astrológico comenzaba con el signo que inicia la primavera: Aries. A cada signo que inicia una estación se le considera cardinal; Aries rige también el primer órgano por arriba: la cabeza. Se pensaba que la cualidad sicológica de los signos cardinales era la de iniciar empresas, la de ser líderes. El lema de Aries es yo soy. Aldana comenzará su epístola a Arias Montano recordando por analogía que Arias es el primero de los humanistas españoles como Aries es el primero de los signos del zodiaco. Tauro es el segundo signo, el signo fijo de tierra y de primavera. Se considera fijo a cada uno de los cuatro signos que están en el apogeo de las cuatro estaciones, primavera, verano, otoño e invierno. La cualidad sicológica que domina en los fijos es la organización, sirven para organizar sin desviarse de su propósito. Son tenaces. Tal vez por esa cualidad se corresponden los cuatro fijos con el emblema de los cuatro evangelistas del tetramorfo. Tauro rige la garganta y su lema es yo tengo. Está gobernado por Venus y rige la casa segunda, la de las posesiones. El tercer signo es Géminis, un signo mutable, porque está entre dos estaciones, entre la primavera y el verano. A los otros tres signos mutables les ocurre lo mismo (Virgo, Sagitario y Piscis), sirven de bisagra entre las estaciones del año. Son por ello comunicadores. Géminis rige las manos, los brazos y el pecho alto. Su lema es «yo pienso o yo comunico», su planeta es Mercurio y rige la casa III, la de los hermanos y la comunicación con el medio cercano. Cáncer, cardinal de agua, inicia el verano. Es el cuarto signo. Su lema es «Yo siento». Su planeta es la Luna y rige el hogar y la relación con la madre. Aries es fuego, Tauro tierra, Géminis aire y Cáncer agua. Con el quinto signo, Leo, reaparece el fuego. Y así sucesivamente. Leo es fijo de fuego. Con él culmina el verano. Rige el corazón y la espalda. Su lema es «Yo quiero». Su planeta es el Sol y rige las capacidades artísticas y los hijos. El sexto signo, Virgo, de tierra mutable, despide al verano y trae el otoño. Rige los intestinos. Su palabra clave es: yo analizo. Como los intestinos, Virgo separa con su análisis lo útil de lo desechable. Tiene a Mercurio y rige el tra-

49 Es magistral sobre los conocimientos herméticos de Dante el libro de «Edy Minguzzi. El enigma fuerte. El código oculto de la Divina Comedia. Barcelona, Editorial Alta Fulla, 2000. Traducción de Fernando Molina Castillo. Ed. original de 1998. Reseñado por mí en la Revista de Poética Medieval, Universidad de Alcalá (en prensa)

50 Cf. Luis Miguel Vicente García. «Notas sobre la concepción del carácter en El Corbacho del Arcipreste de Talavera» Analecta Malacitana. Universidad de Málaga. XXIV, 1 (2001): 131-153 
bajo, el servicio en las relaciones con los demás. Libra es el cardinal de aire, con él comienza propiamente el otoño. Rige los riñones y su lema es yo equilibro. Por eso representará también el matrimonio, el equilibrio entre el tú y el yo. En lo más profundo del otoño está Escorpio, de color vino viejo, fijo de agua, para transformar lo que muere como las hojas del otoño. Su palabra clave es yo deseo o yo callo. Rige los genitales. Le rigen Marte (y Plutón tras su descubrimiento en la era moderna), y su casa es la octava, la casa de la muerte y transformación, de las herencias y de lo oculto. El noveno signo es el del Arquero, Sagitario, fuego mutable que despide el otoño y trae el invierno. Está regido por Júpiter —de ahí su optimismo y vitalidady su lema es yo veo. Rige los muslos que suelen ser destacados como lo es siempre el órgano regido por un signo. Estos órganos además de destacados suelen ser su punto más vulnerable: así, para un Leo su punto vulnerable es el corazón, física y sicológicamente, pues tanto tendrán que cuidarse de los infartos como del orgullo exagerado. Si el opuesto de Sagitario, Géminis, seis casas más atrás, regía los viajes cortos y las relaciones con el medio, Sagitario rige los viajes largos y el estudio de filosofías y religiones de otras culturas. Eso mismo es lo que representa la casa novena. Ambos comparten, como todos los opuestos, alguna característica común que les hace complementarios. En el caso de estos dos opuestos, Géminis y Sagitario, lo común es que se vuelcan en las relaciones personales. Otros opuestos como Virgo y Piscis, se vuelcan en alguna clase de servicio material como el que presta Virgo en ayuda de todo tipo, o más espiritual como el que representa Piscis en hospitales y cárceles. Piscis en la Edad Medita también representa a los enemigos y enfrentamientos. El décimo signo corresponde a Capricornio, regido por Saturno, cardinal de tierra inicia el invierno, con su reposo y profundidad. Representa el honor y los cargos públicos y su lema es «Yo realizo» por su necesidad de llevar a cabo las ideas. Capricornio junto con su opuesto Cáncer representa a los padres, el honor público y el hogar respectivamente, el padre y la madre, la casa X y la casa IV del zodiaco. Es la casa natural de los reyes por ser la casa del honor. En la casa X mirarán los astrólogos los cargos públicos y lo que afecta a la posición social. Rige las rodillas y los huesos en general. El undécimo signo es Acuario, fijo de aire culmina el invierno. Su lema es yo sé, pues es fijo de aire, y el aire representa el mundo de las ideas. Rige las pantorrillas y la circulación y él circula mejor en los grupos de gente. Representa las instituciones que agrupan a los hombres, a los amigos. Y el círculo se cierra con Piscis, el undécimo signo, agua mutable que despide el invierno y trae la primavera otra vez. El círculo se cierra también por los pies, regidos por Piscis, cerrando esa figura de hombre microcosmos que en postura fetal une la cabeza y los pies como se unen Piscis y Aries en el eterno repetirse de los ciclos. El lema de Piscis es yo creo, que de alguna forma, también cierra el círculo iniciado por el yo soy de Aries, el primer signo. Por los pies de Piscis se vuelve a tomar contacto con la tierra y con todo lo otro, mientras que con la cabeza y en Aries se tomaba contacto con la conciencia de sí mismo, yo soy. Aries representa la máxima polaridad del principio masculino activo, lo más próximo a la naturaleza yang del cielo, y Piscis representa la polaridad extrema del principio femenino pasivo, la energía yin de la tierra. El círculo zodiacal trascurre entre la alternancia de un signo yang (Aries) con uno yin (Tauro) hasta que se completa el zodiaco. Un signo masculino seguido siempre de uno femenino. Algo que ilustra el principio hermético del principio del ritmo que gobierna la existencia.

Es el ritmo de las transformaciones en el acontecer universal. A partir de ese ritmo los chinos desarrollaron el I Ching o Libro de las Mutaciones y los babilónicos el zodiaco. Todo parece remitir a un fondo común de filosofía hermética, según puede estudiarse en libros como El kibalión. ${ }^{51} \mathrm{Al}$ margen de si hay demostración al día de hoy de un origen común, sí pueden verse concomitancias esenciales en todos esos conocimientos, unas bases y experiencias comunes a todos ellos. 
El carácter no podía verse como algo desligado de los nexos universales que mantienen al hombre sujeto al cosmos. Aunque estas ideas dieran pie a estereotipos frívolos o infantiles, en sí no eran ideas supersticiosas ni falsas. Los hombres que nacían bajo un mismo signo, sin desprenderse de su singularidad, compartían allgo en común, en el cuerpo y en la sicología. Existe un arquetipo de Escorpio como existe un arquetipo de noviembre. Ambos se basan en la observación y en el carácter cíclico de las manifestaciones. Las culturas han organizado sus arquetipos astrológicos de un modo semejante; y en ellos han reflejado sus aspiraciones. Todas han preferido el círculo para contener a todos los arquetipos en un orden: el arqueómetro. Un círculo dividido en doce fragmentos de 30 grados cada uno, que por su interrelación forman un todo, y donde ninguno prepondera sobre ninguno, pues todos son partes de ese todo que representa el círculo que a su vez representa la vida. Un poema de La Sabiduría de los indios dice así:

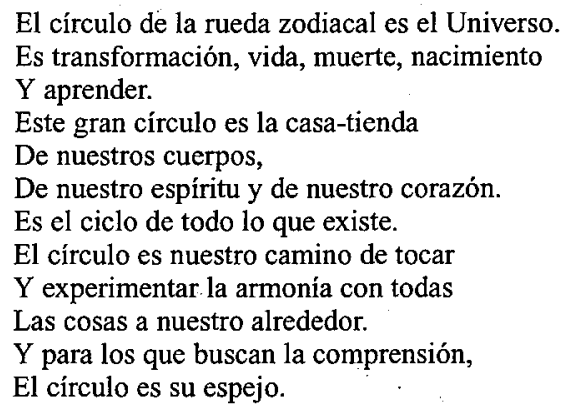

El pensamiento y la literatura medievales y áureos miraron y recrearon el círculo zodiacal, sus planetas y sus casas como un mapa perfecto del cielo. Ni siquiera la revolución copernicana afectó a esas observaciones, pues formaban un arqueómetro con los arquetipos más universales con que el hombre se ha referido a las relaciones del cielo y la tierra o a los nexos universales.

La filosofía de la astrología se fue desarrollando en la Edad Media, inspirada para su desarrollo neoplatónico en figuras como Plotino. En general el pensamiento cristiano despojó a la astrología de su significado predictivo e incorporó la imagen de mundo zodiacal como un modelo astronómico con una prodigiosa imaginería. Aún así Santo Tomás no pudo resistir el empuje de la astrología judiciaria en las traducciones del siglo XIII y admitirá influencias de los planetas y de los astros en la medida que éstos actúan sobre la materia, y por tanto sobre el cuerpo del hombre también. Y como el cuerpo influye en el ánimo, el santo tuvo que aceptar que la astrología podía decir mucho de la anatomía y de la personalidad de los hombres, así como de sus potencialidades y riesgos. En lo que la astrología no tenía poder era en lo espiritual que les permitía el libre albedrío.

Alfonso $\mathrm{X}$ defendió con más fe que el santo la nueva ciencia y la protegió con su legislación al tiempo que la difundía en lengua vulgar. ${ }^{52}$ La sabiduría árabe le había fascinado como a Lulio y como éste había hecho un ingente esfuerzo por comprenderla e incorporársela. Los astrólogos eran para él sabios, científicos. A su manera Alfonso tenía en ellos su era espacial, a los grandes especuladores sobre el universo en una Castilla que tan poco sabía de él. Eran consejeros y así escribían sus revoluciones de los años, que permitían una cierta planificación o previsión de posibles males. Es imposible saber cuánto acertarían en sus pronósticos pero me-

52 Cf. Luis M. Vicente. «La astrología para Alfonso X el Sabio», en Proyección Histórica de España en sus tres culturas: Castilla y León, América y el Mediterráneo. Junta de Castilla y León, 1993: 379-386. Vol. 1. 
recen todo el respeto de Alfonso en su legislación y en su labor científica con ellos. Le fascinó el orden racional tan perfecto que veía en sus libros y los conocimientos prácticos que la astronomía podía aportar al estado, aunque tal vez era su filosofia hermética lo:que más le fascinaba de aquellos conocimientos que venían por vía del Islam y de los judíos y que el mundo clásico también había conocido de alguna manera y aún la primera patrística cristiana se había hecho eco de esos conocimientos, aunque de forma un tanto recelosa al principio. ${ }^{53}$

La imagen del mundo tenía una esencia similar en las grandes culturas y, aunque revestida de nacionalismos, evidenciaba su carácter universal, su carácter científico como se sintió entonces, donde las tres religiones podían coincidir. Si no coincidían en la Teología sí podían coincidir en la Astronomía. De modo que pudieron trabajar juntos para resolver el enigma de la máquina universal y poder funcionar mejor conociendo el ritmo de las transformaciones que ocurren en los distintos ciclos del tiempo que representa el año zodiacal, ciclos que para el ojo del hombre son eternos.

Los siete planetas conocidos entonces representaban modos de actuación o de energía. La luna actuaba sobre las emociones, sobre el elemento agua, los fluidos que causan las emociones: lágrimas, flema, esperma, etc. Afectaba a las mareas, a los nacimientos y era en general la influencia más aceptada incluso por los detractores de la astrología. Todos sabían que había lunáticos. Mercurio afectaba a la inteligencia y a la capacidad de aprender y trasmitir conocimientos. Tiene su casa en Géminis y en Virgo a los que dota para las actividades intelectuales en general y para la observación y la crítica minuciosa. Promueve la comunicación. Marte rige a Aries y a Escorpio, con energía masculina, activa. Con él se relacionan las aptitudes para la guerra y para las actividades viriles en general. Es uno de los arquetipos indispensables para retratar a los mecenas. Cuando Picco della Mirandola piense en un filósofo ideal imaginará que éste deberia tener bien aspectados a Marte y a Mercurio. Mercurio por su capacidad intelectual pero también Marte para conferir a esa capacidad la suficiente fuerza y tenacidad para materializarla. ${ }^{54}$

Júpiter aporta la energía del corazón, la vitalidad, la generosidad y el entusiasmo para realizar las cosas. Rige a Sagitario y a Piscis y tampoco falta en las imaginarias cartas astrológicas que los poetas construyen para sus mecenas. Un Júpiter espléndido tiene siempre que augurar en esas cartas la opulencia y la magnanimidad. Se considera un planeta afortunado en la Edad Media, frente a Marte, la Luna o Saturno que pueden ser desafortunados, o Mercurio, que se considera neutro. Venus y el Sol también serán considerados planetas de fortuna. Venus rige la actividad sensual, la belleza. Rige a Tauro y a Libra. Bajo el signo de Venus dice el Arcipreste de Hita que nació. ${ }^{55}$ Una Venus generosa con sus dones será la que reaparezca una y otra vez en los dezires para regalar los oídos de los mecenas a los que Venus da belleza, arte, buenos matrimonios y todo el esplendor de lo bello. El Sol es el planeta rey y por lo mismo también es el arquetipo rey a la hora de retratar a mecenas o a santos y apóstoles. Rige a Leo en la plenitud del verano. Representa el poder, la salud, la riqueza y también, como Apolo, la creatividad para la poesía y el arte.

Los planetas en su movimiento forman aspectos unos con otros: algunos de estos aspectos son positivos - como los trígonos, sextiles y en general conjunciones; otros son negativos,

53 Cf. Luis M. Vicente. «San Agustín, San Gregorio y San Isidoro ante el problema de las estrellas: fundamentos para el rechazo frontal de la astrología» Revista Española de Filosofia Medieval. Universidad de Zaragoza 8 (2001): 187-203.

54 Cf. Mi reseña sobre Manifiestos del Humanismo. Petrarca, Bruni, Valla, Picco della Mirandola, Alberti. Edición de María Morrás, Barcelona: Península, 2000) Voz y Letra (2001): 142-148.

$55 \mathrm{Cf}$. Luis M. Vicente. «La astrología en el Libro de buen amor. Fuentes y problemas sobre el uso de conceptos astrológicos en la literatura medieval española.» Revista de Literatura. CSIC, Tomo LXI, n 122, 1999 : 333 347. 
como las oposiciones y cuadraturas. Sus energías colaboran o sus energías antagonizan. Mirando además en qué casas surgen esos aspectos, el astrólogo puede pensar sobre qué área de la vida van a actuar esos planetas y esos aspectos entre planetas. Así si hay, por ejemplo, una conjunción del Sol y de Júpiter en Tauro y en la casa II, probablemente el astrólogo piense que para la persona o el asunto nacido en ese momento del cosmos, los bienes materiales y en especial la casa tendrán mucha importancia. Todos esos arquetipos refuerzan esa idea. Conociendo el valor dado a los distintos arquetipos (signos, planetas, casas, aspectos, ascendente, etc) el astrólogo puede hacer una lectura coherente con la carta astrológica, interpretando el valor de esos arquetipos en la singular disposición que adquieren en un momento dado del tiempo. Pero no es la coherencia de una lectura matemática. Cabe la interpretación y la imaginación, y a la hora de interpretar una carta no creo que pudieran darse dos lecturas idénticas. La lectura podía hacerse en varios sentidos y ahí entraba la particular personalidad del astrólogo para interpretar la disposición de una carta. Por eso tampoco podrían coincidir dos revoluciones de los años, o calendarios predictivos para la vida del reino durante un año. Por eso también preocupa el asunto a los legisladores para distinguir a los charlatanes de los que se basan en la ciencia de la astrología. Pero en principio, como se ve en la historia del rey Alcaraz en El libro de buen amor, varias lecturas distintas en su forma no significa que no sean compatibles en lo que subrayan esencialmente: así la muerte del protagonista de esa historia se produce de todas las maneras en que había sido pronosticada por los astrólogos, aunque sus versiones parecían contradictorias.

La Iglesia en todo caso intentó castigar todo lo que sonara a determinismo o conocimiento del futuro reservado a Dios y a veces a sus profetas. Tan sólo con sentido poético podían usarse los arquetipos astrológicos para adornar a los mecenas o a los iluminados de la Iglesia, o para ciertas cosas relativas al clima y a la medicina. La Iglesia sí incorporó la idea del hombre como microcosmos. Sólo tenía problemas con la astrología judiciaria y con aquello de la astrología que pudiera justificar los destinos de los hombres y eximirlos de la responsabilidad de su libre albedrío para hacerse a sí mismos. Religión y Astrología no eran en sí incompatibles pero políticamente solían corresponder a clanes distintos, por lo que la tensión obedecía al modelo de sociedad que había, con una disciplina religiosa tan intransigente con la libertad de credo y de conducta. Como corte, la Iglesia también gustó de los astrólogos y Dante se hizo astrólogo poético para significarla y alabarla. También el Cartujano se hace astrólogo de este tipo para reinventar el horóscopo de cada uno de los doce apóstoles. ${ }^{56}$ Pèro esta astrología presenta un componente imaginativo y literario muy notable, que no proviene de la astrología real y que configura la astrología retórica de los dezires, a semejanza sobre todo de la de Dante.

Una astrología así sobrevive en la Égloga II de Garcilaso, en la sección dedicada a trazar el retrato del Duque de Alba, como modelo de hombre mesurado cuyo ejemplo puede servir de cura al desesperado Albanio, loco de amor. El retrato del Duque se hace con arquetipos astrológicos a la usanza del dezir alegórico. Y los natalicios también usaron de esta astrología, como algunos de los escritos por Fray Luis. En el barroco esta misma astrología poética puede aparecer ya parodiada y convertida en sátira o muy sutilmente camuflada como en el caso de Góngora. 57

Otro temas de la astrología que tomó la literatura con frecuencia fue el de los cuatro elementos que conforman el mundo sublunar: tierra, agua, aire, fuego, de más pesado a más li-

56 Cf. Luis M. Vicente, «La astrología en Los doce triunfos de los doce apóstoles del Cartujano. Revista de Literatura. Consejo Superior de Investigaciones Científicas, 1992: 47-75.

57. Cf. Luis M. Vicente, «Notas sobre imaginería musical y amor en la poesía de Góngora». Edad de Oro, 12. Ediciones de la Universidad Autónoma de Madrid (2003): 205-220 y «El lenguaje hermético en la Fábula de Polifemo y Galatea de Góngora» Edad de Oro, 13. Ediciones de la Universidad Autónoma de Madrid (2003): en prensa. 
gero. La tierra y el agua, femeninos, se complementan, se necesitan mutuamente en una proporción equilibrada. Con el agua la tierra da frutos, y el agua con la tierra encuentra límite y se mezcla. El aire y el fuego también se necesitan de igual manera. Entre ellos ya se establece esa química de atracciones que ilustran los principios herméticos de la generación y de la polaridad. ${ }^{58}$

Los signos que comparten un elemento, agua, por ejemplo, comparten también una característica importante, los tres, Cáncer, Escorpio y Piscis forman un triángulo de agua, son signos emocionales por antonomasia y eso les une fuertemente. Lo mismo pasa con los triángulos de aire - Géminis, Libra, Acuario-; de fuego - Aries, Leo, Sagitario; o de tierra - Tauro, Virgo, Capricornio. La unión de los signos por afinidad con los de su mismo elemento o por atracción hacia su opuesto y complementario es, estadísticamente, mucho más frecuente que las otras combinaciones posibles. Este fue uno de los ejercicios que se propuso Jüng para lidiar desde las exigencias del método científico moderno con la credibilidad de las clasificaciones astrológicas. Esa es una de las primeras experiencias que se pueden hacer para comprobar si el sistema de relaciones que propone la astrología tiene algún fundamento en la realidad o si es arbitrario. Las estadísticas son muy interesantes en este sentido. Y vienen a confirmar que las clasificaciones y relaciones de la astrología se inspiran en la observación de la realidad desde la regularidad de los ciclos. También en el establecimiento de arquetipos físicos o anatómicos para cada signo o planeta está lo estadístico y la observación de un corpus amplio de personas bajo semejantes circunstancias espacio-temporales. Así se determina un prototipo de cejas capricornianas, o de mirada mercurial, o de espalda leonina, etc. Para un astrólogo la mirada de un Géminis y la de un Escorpio, por ejemplo, debían ser fácilmente reconocibles, observadas atentamente. La anatomía astrológica tampoco era ciencia ficción, aunque se trataba de arquetipos y no de detalladas descripciones. A veces el arquetipo astrológico en el físico de una persona es tan visible como el gran parecido genético que muestran algunos hijos respecto de sus progenitores. En este caso si uno conoce al padre no se sorprende del parecido del hijo. De igual manera el astrólogo o estudiante de astrología ve en un Leo, por ejemplo, los rasgos que le da el arquetipo Leo, como si el arquetipo fuera otro padre al que se parece. Así es como se ven los arquetipos astrológicos en la realidad física, simplemente viéndose. Cuando un astrólogo ve a simple vista a un Sagitario, por ejemplo, no se está inventando nada (salvo que no atine), normalmente está reconociendo un arquetipo astrológico que imprime naturaleza a la persona y que lo lleva tan visible como otras herencias genéticas y culturales. Por lo tanto en sí la astrología no es un asunto de creencias. Conviene dejar ese tópico a un lado cuando uno se pone a estudiar sus fundamentos. Todo su sistema emana de la observación de situaciones arquetípicas que se repiten de un modo eterno para nuestra apreciación. Situaciones análogas, analogía universal. En el espacio de esos ciclos vuelven a repetirse cosas y circunstancias semejantes, rasgos comunes y naturalezas similares.

Para los astrólogos todas las esferas del vivir se reflejan en el mapa de los cielos: la raza, la geografía, las uniones personales, los talentos y desgracias, todo encuentra expresión en el mapa del cielo.

Mas la ambición de conocer los secretos del cielo mata a Alejandro y desencanta a Sor Juana en su Sueño. El Fausto podía ser un astrólogo. O un gran mago. De Merlín perdido en la leyenda se llegó a Nostradamus y a Paracelso. Del más o menos explícito Dante se llegó al jeroglífico de Góngora.

58 Sobre el principio de Generación leermos en el Kibalion: «La generación existe por doquier; todo tiene sus principios masculino y femenino; la generación se manifiesta en todos los planos» (op. cit., pág 24), y sobre el principio de polaridad leemos: «Todo es doble, todo tiene dos polos; todo, su par de opuestos: los semejantes y los antagónicos son lo mismo; los opuestos son idénticos en naturaleza, pero diferentes en grado; los extremos se tocan; todas las verdades son semiverdades; todas las paradojas pueden reconciliarse» (op. cit., pág. 19). 
La Astrología y là Alquimia formaban una sola filosofía en el mundo hermético. La Teosofia volveria a intentar integrar todo el saber espiritual de Occidente, sin dejar de aspirar como los Templarios a un conocimiento integral sobre el papel del hombre en la Creación. Una aspiración que está en la astrología como filosofía, más que como procedimiento de adivinación. Porque la astrología aspiraba a comprender la mente de Dios al organizar su creación y los artistas trataban de imitar ese orden con su creatividad.

\section{OBRAS CITADAS ${ }^{59}$}

Amadou, Robert. «Le Message astrologique de Plotin» En L'Astrologie. Cahiers de l'Hermétisme. Paris: Albin Michel, 1985. 13-49.

Anderson, Carol Susan. Divine Governance, Miracles and Laws of Nature in the Early Middle Ages: The <De mirabilibus Sacrae Scripturae>. Tesis doctoral. Los Angeles: University of California, Los Angeles, 1982.

Bergua, Juan B. Mitología universal. 2 tomos. $2^{\text {a }}$ ed. Madrid: Ediciones Ibéricas, 1960.

Bouché-Leclerq, A. L'Astrologie grecque. Paris: Culture et Civilisation, 1899.

Catholic Encyclopedia Vol. 2. New York: Robert Appleton Company, 1907.

Fontaine, Jacques. «Isidore de Seville et l'Astrologie.» Revue des Etudes Latines 31 (1953): 271-300. Recogido en Tradition et actualité chez Isidore de Séville. London: Variorum Reprints, 1988. 271-300.

Gettings, Fred. Dictionary of Astrology. London, Boston y Henley: Routledge \& Kegan Paul, 1985.

Jones, Marc Edmund. How to Learn Astrology. Philadelphia: David McGray, 1954.

Lainstner, M. L. W. "The Western Church and Astrology During the Erarly Middle Ages.» The Harvard Theological Review. 34 (Oct.1941): 251-276.

Lemay, Richard. «The True Place of Astrology in Medieval Science and Philosophy: Towards a Definition.» Astrology, Science and Society. Historical Essays. Ed. Patrick Curry. New Hampshire: The Boydell Press, 1987. 57-76.

Wedel, Theodore Otto. The Mediaeval Attitude Toward Astrology, Particularly in England. New Haven: Yale University Press, 1920.

Luis Miguel Vicente García Universidad Autónoma de Madrid

Facultad de Filosofía y Letras

Dpto. Filología Española

28049 Cantoblanco (Madrid)

Luismiguel.vicente@uam.es

59 Para evitar repeticiones, no se consignan aquí las obras que se han citado completas en las notas a pie de página. 